ISSN 1979-5572 (print)

ISSN 2541-6480 (online

http://ejurnal.iainpare.ac.id/index.php/kuriositas

KURIOSITAS

Media Komunikasi Sosial dan Keagamaan

Volume 11

No. 1, Juni 2018

Halaman 33-45

\title{
PENGGUNAAN MEDIA FACEBOOK BAGI \\ PENINGKATAN MOTIVASI BELAJAR SISWA MATA \\ PELAJARAN PENDIDIKAN AGAMA ISLAM
}

\author{
Marwiah \\ SMPN 02 lasinrang \\ marwiahlasinrang@gmail.com
}

\begin{abstract}
This study aims to determine the use of media facebook on students, and to determine the role of facebook media to increase the motivation to learn PAI students in SMPN 2 Lanrisang. This type of research is descriptive qualitative research. Qualitative method, preferably observation, interview, documentation. This research used Dougherty \& Pritchard theory in Bauer. That is Role perception and Role Expectation, with aspect of role: a) Impersonal, b) Working behavior, c) Controlling, d) Behavior change, and e) Various role / activity. The results of this study were: 1) media faceboook has been used in students SMPN 2 Lanrisang, Facebook for the students SMPN 2 Lanrisang not only serves as a social network but has become a medium of learning with the use of group features in facebook media. 2) facebook media contributes to the improvement of students' learning motivation in SMPN 2 Lanrisang, especially on learning of Islamic Religious Education, this is seen among the students who are active in the group facebook PAI
\end{abstract}

Keywords: Facebook, Students Motivation, Islamic Education 


\begin{abstract}
ABSTRAK
Penelitian ini bertujuan untuk mengetahui penggunaan media facebook pada siswa, dan untuk mengetahui peran media facebook terhadap peningkatan motivasi belajar PAI siswa di SMPN 2 Lanrisang. Jenis penelitian ini adalah penelitian kualitatif yang bersifat deskriptif. Metode kualitatif, lebih mengutamakan observasi, wawancara, dokumentasi. Penelitian ini menggunakan teori Dougherty \& Pritchard dalam Bauer. yaitu Role perception: dan Role Expectation, dengan aspek peran: a) Impersonal, b) Perilaku kerja, c) Pengendalian, d) Perubahan perilaku, dan e) Ragam peran/kegiatan. Hasil penelitian menunjukkan bahwa:1) media faceboook telah digunakan pada peserta didik SMPN 2 Lanrisang, Facebook bagi kalangan peserat didik SMPN 2 Lanrisang bukan saja berfungsi sebagai jejaring sosial saja tetapi telah menjadi media pembelajaran dengan penggunaan fitur group di media facebook. 2) Media facebook berperan terhadap peningkatan motivasi belajar siswa di SMPN 2 Lanrisang, dan sebagai media diskusi khususnya pada pembelajaran Pendidikan Agama Islam, hal ini terlihat pada kegiatan peserta didik yang aktif dalam group facebook PAI.

Kata Kunci: Facebook, Motivasi Belajar, PAI
\end{abstract}

\title{
PENDAHULUAN
}

Pendidikan adalah sebuah proses pembentukan manusia seutuhnya yang dapat dipengaruhi oleh banyak faktor pendukung terciptanya suatu pendidikan yang sempurna. Salah satunya adalah keberadaan alat (media) pendidikan (Syaiful Bahri dan Azwan Zain: 2002). Era globalisasi dan perkembangan ilmu pengetahuan dan teknologi yang semakin canggih, penyebaran informasi serta akses telekomunikasi dan transportasi semakin lebih cepat dan mudah.

Teknologi pendidikan merupakan media komunikasi yang berkembang secara pesat sekali yang dapat dimanfaatkan dalam pendidikan. Media teknologi lazim disebut hardware antara lain berupa TV, 
radio, video tape, dan komputer. Adapun pengembangan, penerapan dan penilaian sistem-sistem, teknik dan alat bantu untuk memperbaiki dan meningkatkan proses belajar manusia, kita sebut dengan istilah software (Nasution:2005).

Informasi memiliki kekuatan, baik membangun maupun merusak, menjadi simbol dan kebutuhan masyarakat modern (masyarakat informasi) (Zalkarimein Nasution:1989). Informasi dapat bersumber dari manusia yang bisa berupa ide dan peristiwa (event). Untuk dapat menjadi informasi, ide harus dinyatakan baik dalam bentuk isyarat (simbol verbal). Informasi dapat dicari, dikumpulkan dan diolah menjadi informasi tercetak, informasi audio, dan informasi audio visual statis maupun gerak (S. Nasution: 2006). Teknologi informasi dapat diartikan sebagai teknologi elektronika yang mampu mendukung percepatan dan meningkatkan kualitas informasi, yakni melalui internet, percepatan arus informasi ini tidak mungkin lagi dibatasi oleh ruang dan waktu (JB Wahyudi:1992 ).

Media yang ada di dalam internet yaitu terdapat situs facebook yang ditemukan oleh Mark Zuckerberg pria berusia 24 tahun yang berasal dari California Amerika Serikat. Facebook didirikan pada tanggal 4 Febuari 2004, yang waktu itu facebook hanya terbatas untuk kalangan dari Universitas Harvard dan lalu berkembang ke kampus Stanford (Sartika Kurniali : 2009).

Facebook masih berpotensi berkembang di Indonesia. Jumlah anggota dalam kisaran satu juta pada akhir Mei 2009 masih mungkin meningkat drastis pada bulan-bulan berikutnya. Sebagai perbandingan, friendster di masa kejayaanya sanggup meraup delapan juta pengguna. Sementara itu saat ini muncul indikasi migrasi besar-besaran pengguna friendster ke facebook.

Salah satunya yang dapat dimanfaatkan dalam facebook adalah aplikasi group. Group ini bisa dijadikan media pembelajaran yang efektif, yaitu sebagai tempat diskusi dan sharing tentang materi pembelajaran. Pendidikan agama Islam sebagai salah satu mata pelajaran di SMPN 2 Lanrisang, dalam pelaksanaannya masih menunjukkan berbagai 
permasahalan yang kurang menyenangkan. Seperti halnya proses pembelajaran Pendidikan Agama Islam (PAI) di sekolah saat ini masih sebatas sebagai proses penyampaian "pengetahuan tentang Agama Islam." Hanya sedikit yang arahnya pada proses internalisasi nilai-nilai Islam pada diri siswa. Proses internalisasi tidak secara otomatis terjadi ketika nilai-nilai tertentu sudah dipahami oleh siswa. Artinya, metode yang selama ini digunakan guru ketika mengajar PAI berpeluang gagal pada proses internalisasi nilai-nilai agama Islam kepada siswa, hal ini disebabkan siswa kurang termotivasi untuk belajar materi PAI.

Metode pembelajaran agama Islam yang selama ini lebih ditekankan pada hafalan (padahal Islam penuh dengan nilai-nilai yang harus dipraktekkan dalam perilaku keseharian), akibatnya siswa kurang memahami kegunaan dan manfaat dari apa yang telah dipelajari dalam materi PAI yang menyebabkan tidak adanya motivasi siswa untuk belajar PAI. Dalam proses pembelajaran, motivasi memegang peranan penting, yaitu sebagai pendorong siswa dalam belajar dan merupakan syarat mutlak dalam belajar. Di sekolah, sering terdapat siswa yang malas, main game gadget, suka membolos dan lain sebagainya.

Berdasarkan dari latar belakang di atas, penulis terdorong untuk melakukan penelitian, untuk mengetahui apakah pengaruh penggunaan facebook yang akhir-akhir ini marak dilakukan oleh siswa-siswa khususnya siswa SMPN 2 Lanrisang dapat meningkatkan motivasi belajar siswa, atau sebaliknya. Oleh karena itu, penulis akan melakukan penelitian yang berjudul: "Peran Penggunaan Media Facebook: Relasi Terhadap Peningkatan Motivasi Belajar PAI Siswa di SMPN 2 Lanrisang Kab. Pinrang".

\section{METODE}

Jenis penelitian ini merupakan penelitian kualitatif yang bersifat deskriptif, yakni menekankan pada kedalaman data yang didapatkan, semakin dalam dan detail data yang didapatkan, maka semakin baik kualitas dari penelitian ini. Peneliti ikut serta dalam peristiwa/kondisi yang 
sedang diteliti (Lexy J. Moleong :2007). Penelitian ini menggunakan pendekatan penelitian studi kasus, meneliti suatu kasus tertentu yang ada dalam masyarakat yang dilakukan secara mendalam untuk mempelajari latar belakang, keadaan, dan interaksi yang terjadi.

Data primer, semua data yang diperoleh langsung dari informan (Kepala sekolah, pendidik, pegawai (staf), dan peserta didik). Melalui wawancara terstruktur dan hasil observasi langsung di SMPN 2 Lanrisang Pinrang. Data sekunder adalah data yang mendukung data primer, yakni data yang diperoleh dari literatur seperti buku-buku, majalah, dokumen, maupun referensi

\section{PEMBAHASAN}

\section{Penggunaan Media Facebook pada siswa SMPN 2 Lanrisang.}

\section{Impersonal}

Menurut Scott et al. dalam Kanfer jika dikaitkan dengan facebook, bahwa facebook telah bersifat impersonal, posisi facebook telah menjadi subjek bukan lagi objek. Selebihnya facebook merupakan salah satu fasilitas yang masuk ke dalam kategori sosial networking website yang dalam bahasa Indonesianya sering disebut, jaringan sosial. Situs yang tidak hanya digunakan untuk melakukan pertemanan tapi juga untuk tetap mengupdate diri anda dengan berita dan kabar terbaru tentang teman pengguna situs tersebut. Dalam kedua situs tersebut pengguna sama sama dapat berbagi profile, foto dan video.

Akun group facebook, SMPN 2 Pendais merupakan group facebook, yang dikelola secara khusus oleh Guru Mata Pelajaran Pendais (Pendidikan Agama Islam) dan siswa yang telang tergabung sebanyak 35 orang. Penggunaan group facebook pada kalangan siswa di SMPN 2 Lanrisang, sebagian besar telah tergabung dengan group facebook. Partisipasi siswa dengan group faceboook Pendais seperti yang diungkapkan oleh beberapa informan:Dandy mengemukakan bahwa "Menurut saya group facebook itu merupakan suatu sarana belajar yang praktis dengan jejaring sosial 
melalui dunia maya". Rahmawati menjelaskan bahwagroup facebook itu adalah merupakan salah satu metode belajar dari situs pertemanan dalam jejaring sosial".

Group Facebook Pendais SMPN 2 Lasinrang, telah memfasilitasi pembentukan proses pembelajaran di kalangan siswa dengan guru tanpa harus ada kontak langsung antara siswa dengan guru, mereka dapat mengikuti perkembangan melalui diskusi dan chatting dalam group yang sengaja dibuat dengan harapan untuk meningkatkan motivasi belajar mereka melalui media facebook. Selama ini terkesan mereka marak menggunakan facebook hanya untuk cari-cari teman dan berdiskusi di dunia maya jarang sekali mereka memanfaatkannya untuk belajar. Apalagi belajar dengan panduan guru di dunia maya mereka hampir tidak menggunakannya. Mereka lebih memilih sibuk chattingan dengan temanteman baru mereka baik yang dikenal sebelumnya ataupun yang baru mereka kenal di facebook atau mereka memilih bermain game, karena menurut mereka mungkin itu lebih menarik.

\section{Perilaku Kerja}

Facebook telah mempengaruhi perilaku kerja individu, media sosial telah menjadi kebutuhan dalam perilaku kerja masyarakat. Group facebook sudah menjadi kebutuhan khususnya dikalangan siswa di SMPN 2 Lanrisang, karena selain mereka gunakan untuk berinteraksi atau berhubungan dengan teman-teman sesama komunitasnya, melalui group facebook pendais, mereka bisa dengan mudah memperoleh berbagai materi dan informasi yang sudahataupun belum dipelajari di sekolah. Group facebook dapat dibuka dan digunakan dimana dan kapan saja, tergantung fasilitas yang dipakai. Bisa menggunakan handphone, smartpohone, tablet, notebook, laptop dan komputer yang penting terkoneksi dengan internet.

Penggunaan group facebook sebagai salah satu media pembelajaran, telah menambah model pembelajaran yang dulunya pembelajarn dilakukan secara langsung dan tatap muka sekarang melalui group facebook atau melalui dunia maya, pembelajaran bisa berlangsung tanpa tatap 
muka, tetapi melalui jaringan komunikasi online. Seperti gambar 1 pada lampiran, menggambarkan proses pembelajaran melalui group facebook pendidikan agama Islam, dengan materi qalqalah sugra dan qalqalah kubra. Siswa ditugaskan untuk menjawab pengertian qalqalah. Ada beberapa siswa yang telah menjawab dan memberikan komentar dan tugas tersebut telah dilihat $20 \mathrm{kali}$, atau siswa yang telah membaca tugas tersebut sebanyak 20 orang.

Menurut kepala sekolah SMPN 2 Lanrisang, bahwa: proses pembelajaran melalui group facebook sejauh ini telah memberikan dampak yang positif. Hal tersebut tergambar dari tampilan tersebut telah dilihat oleh banyak siswa. Hal tersebut menunjukkan bahwa model pembelajaran online diminati oleh siswa. Perilaku siswa dalam belajar memberikan efek positif ditandai dengan perubahan perilaku yang ditunjukkan yang tadinya kurang bergairah menjadi termotivasi dengan melihat temantemannya yang mulai asyik berdiskusi pada group yang mereka buat sehingga model pembelajaran luar kelas ini bisa dikembangkan dan dilanjutkan secara kontinyu.

\section{Pengendalian}

Penggunaan situs jaringan pertemanan tidak hanya menimbulkan pengaruh dan dampak secara langsung pada orang yang sedang menggunakan fasilitas ini, tetapi juga secara tidak langsung pada orang lain dan lingkungan. Sama dengan hal lainnya, penggunaan situs jejaring sosial khususnya facebook tidak akan menimbulkan dampak yang buruk jika digunakan sebagaimana mestinya, normal, dan tidak berlebihan. Namun, jika terlalu sering menggunakan fasilitas ini, dikhawatirkan akan terjadi ketergantungan yang tidak sehat, serta penyalahgunaan fasilitas yang tidak benar.

Berdasarkan uraian di atas teori yang dikemukan Sarlito Wirawan, bahwa peran facebook menggambarkan interaksi sosial dalam terminology aktor-aktor yang bermain sesuai dengan apa-apa yang ditetapkan oleh budaya. Sesuai dengan teori ini, harapan-harapan peran merupakan 
pemahaman bersama yang menuntun kita untuk berperilaku dalam kehidupan sehari-hari. Hal ini yang terjadi bahwa facebook menjadi model interaksi sosial yang baru dan telah terinternalisasi dan membudaya dalam kehidupan sehari.

Menurut Berry, bila yang diartikan dengan peran adalah perilaku yang diharapkan dari seseorang dalam suatu status tertentu, maka perilaku peran adalah perilaku yang sesungguhnya dari orang yang melakukan peran tersebut. Perilaku peran mungkin berbeda dari perilaku yang diharapkan karena beberapa alasan. Hubungannya dengan pengendalian group SMPN 2 Pendais terkadang menemukan kendalakendala dalam kegiatan dan aktivitasnya antara lain :

1. Tidak ada dukungan dari beberapa pihak antara lain orang tua

2. Jaringan yang biasa tidak bagus karena cuaca

3. Tidak memiliki kuota mengakibatkan tidak bisa bergabung di group

4. Karena materinya sudah tahu jadi malas berdiskusi lagi

Jadi siswa dalam group ini berperan sebagai pencari dan penemu informasi dan sumber informasi tetap dikendalikan oleh guru. Ini merupakan suatu tindakan yang membatasi siswa untuk melakukan suatu kegiatan berdasarkan tujuan dan ketentuan yang telah disepakati bersama agar dapat dilakukan dengan sebaik-baiknya. Orang yang sukses adalah orang yang terorganisasi dengan baik, dan memiliki tujuan hidup, memiliki pengendalian diri dan cinta dalam hatinya, dan mencintai pengetahuan yang bisa membantu mereka untuk menciptakan kondisi yang kondusif, dimana dapat terjalin kerjasama yang baik di dunia maya maupun di dunia nyata sehingga apa yang menjadi tujuan akhir dapat tercapai 


\section{Peran Penggunaan Facebook dalan peningkatan motivasi belajar PAI Peserta didik SMPN 2 Lanrisang.}

\section{Perubahan Perilaku}

Penggunaan jejaring sosial facebook saat ini memang sedang marak digemari oleh berbagai kalangan terutama siswa sendiri, disini informan bersikap terbuka dalam menerima suatu perkembangan teknologi dan kebanyakan menilainya secara positif dan negatif. Senada dengan Gayatri, bersikap terbuka dan menilai adanya jejaring sosial facebook dalam 2 sisi yakni positif dan negatif, "mempunyai facebook itu ada baik dan ada pula buruknya. Baiknya sebagai jejaring sosial sarana untuk menambah teman, memberikan informasi bisa juga untuk sarana belajar. Di facebook ada aplikasi group bisa sebagai tempat diskusi".

Penggunaan group facebook Pendais SMPN 2 Lanrisang, telah membawa perubahan perilaku bagi peserta didik, hal ini terlihat pada keaktifan dalam group facebook, walaupun hanya memberikan "like", dan bahkan memberikan komentar. Gambar 10 pada lampiran, merupakan bagian dalam pembelajaran PAI yaitu shalat dhuha.

Terkait dengan penggunaan group facebook, motivasi yang ada pada diri siswa sangat penting dalam kegiatan belajar. Ada tidaknya motivasi seseorang individu untuk belajar sangat berpengaruh dalam proses aktivitas belajar itu sendiri. Menurut Uno, indikator motivasi belajar dapat diklasifikasikan sebagai berikut:

1. Adanya hasrat dan keinginan berhasil

2. Adanya dorongan dan kebutuhan dalam belajar

3. Adanya harapan dan cita-cita masa depan

4. Adanya penghargaan dalam belajar

5. Adanya kegiatan yang menarik dalam belajar

6. Adanya lingkungan belajar yang kondusif (Hamzah B. Uno : 2008).

Gambaran indikator motivasi belajar, adanya hasrat dan keinginan berhasil sebagaimana Abdul Rahman mengemukakan bahwa: "tergabung 
dalam group facebook, merupakan kewajiban bagi semua siswa kelas 8, dan juga merupakan bagian dalam penilaian pada pelajaran Pendidikan Agama Islam, sehingga harus selalu aktif dan memberikan komentar, apalagi pada saat guru pendais memberikan tugas pada group fecebook."

Indikator adanya dorongan dan kebutuhan dalam belajar, tergambar pada keaktifan siswa dan siswi SMPN 2 Lanrisang pada group facebook terlihat antusias siswa dalam memberikan tanggapan dalam like dan komentar. Sebagaimana Nurhayati mengemukakan pendapat bahwa “ facebook bukan saja sebagai gaya hidup, tapi juga menjadi media dalam pembelajaran. Groupfacebook yang dibuat oleh guru pendais merupakan bentuk dorongan dan kebutuhan dalam belajar."

Indikator adanya harapan dan cita-cita dalam masa depan, terlihat dalam partisipasi peserta didik dalam group facebook, dimana peserta didik terlibat dalam group facebook mengalami peningkatan. Awalnya sekedar melihat tampilan group saja, lama-kelamaan mereka ikut berkomentar juga.

Indikator adanya penghargaan dalam belajar terlihat pada pendapat guru pendais, yang mengemukakan bahwa: "pernyataan verbal atau penghargaan dalam bentuk lainnya terhadap prilaku yang baik atau hasil belajar anak didik yang baik merupakan cara paling mudah dan efektif untuk meningkatkan motif belajar anak didik kepada hasil belajar yang lebih baik. Pernyataan seperti "bagus", "hebat" dan lain-lain disamping akan menyenangkan siswa, pernyataan verbal seperti itu juga mengandung makna interaksi dan pengalaman pribadi yang langsung antara siswa dan guru, dan penyampaiannya konkret, sehingga merupakan suatu persetujuan pengakuan sosial, apalagi kalau penghargaan verbal itu diberikan didepan orang banyak."

Adanya kegiatan yang menarik dalam belajar, dalam group facebookbaik simulasi maupun permainan merupakan salah satu proses yang sangat menarik bagi siswa. Suasana yang menarik menyebabkan proses belajar menjadi bermakna. Sesuatu yang bermakna akan selalu 
diingat, dipahami, dan dihargai. Seperti kegiatan belajar seperti diskusi, brainstorming, pengabdian masyarakat dan sebagainya.

Sedangkan indikator adanya lingkungan belajar yang kondusif tergambar pada komentar guru pendais yang mengemukakan bahwa, "pada umumnya motif dasar yang bersifat pribadi muncul dalam tindakan individu setelah dibentuk oleh lingkungan. Oleh karena itu motif individu untuk melakukan sesuatu misalnya untuk belajar dengan baik, dapat dikembangkan, diperbaiki, atau diubah melalui belajar dan latihan, dengan perkataan lain melalui pengaruh lingkungan Lingkungan belajar yang kondusif salah satu faktor pendorong belajar anak didik, dengan demikian anak didik mampu memperoleh bantuan yang tepat dalam mengatasi kesulitan atau masalah dalam belajar."

\section{SIMPULAN}

Media facebook telah digunakan pada peserta didik SMPN 2 Lanrisang sebagai media dalam pertemanan tetapi berfungsi sebagai jejaring sosial saja tetapi telah menjadi media pembelajaran dengan penggunaan fitur group di media facebook. Fitur group digunakan peserta didik sebagai sarana diskusi dan sharing informasi tentang pelajaran agama Islam di sekolah. Media facebook berperan terhadap peningkatan motivasi belajar peserta didik di SMPN 2 Lanrisang, khususnya pada pembelajaran Pendidikan Agama Islam, hal ini terlihat pada kalangan peserta didik SMPN 2 Lanrisang yang aktif dalam group facebook PAI yang menjadi media atau sarana peserta didik dan guru dalam belajar dan berdiskusi. Dalam group PAI tersebut siswa dapat memberikan komentar dan masukan serta pertanyaan tentang materi yang telah dipelajari pada saat pembelajaran di sekolah, jika ada materi PAI yang belum dipahami dapat dilanjutkan dalam group facebook, dan bahkan siswa dapat bertanya tentang materi-materi seputar agama Islam yang tidak dipelajari di sekolah. Sehingga peserta didik akan lebih termotivasi dalam belajar dan lebih banyak waktu dalam belajar dan prestasi belajar peserta didik akan meningkat pula. 
Kuriositas: Media Komunikasi Sosial dan Keagamaan

Vol. 11 No.1, Juni 2018: h.33-45

\section{REFERENCE}

(1) Arikunto, Suharsimi. Proses Penelitian Suatu Pendekatan. Cet. XIII; Jakarta : Rineka Cipta, 2006.

(2) Bahri, Syaiful. Zain, Azwan. Strategi Belajar Mengajar .Jakarta: Rineka Cipta, 2002.

(3) Faizal, Sanafiah. Format-format Penelitian Sosial. Cet. V; Jakarta: PT. Raja Grafindo Persada, 2001.

(4) Kurniali, Sartika. Step By Step Facebook. Jakarta: Alex Media Komputindo, 2009.

(5) Moleong, Lexy J. Metode Penelitian Kualitatif . Bandung: Remaja Rosdakarya, 2007.

(6) Mappanganro, Implementasi Pendidikan Islam Di Sekolah Ujung Pandang: Yayasan Ahkam, 1996.

(7) Margono, S., Metodologi Penelitian Pendidikan, Jakarta: Rineka Cipta, 2003.

(8) Meier, Dave, The Accelerated Learning HandBook Penterjemah Rahmani Astuti, Bandung: Kaifa, 2005.

(9) Moleong, Lexi J., Metodologi Penelitian Kualitatif Bandung: Remaja Rosda Karya, 2003.

(10) Mufarokah, Anissatul. Strategi Belajar Mengajar, Yogyakarta: Teras, 2009.

(11) Muhaemin, Pengembangan Kurikulum Pendidikan Agama Islam di Sekolah, Madrasah, dan Perguruan Tinggi Jakarta: Rajawali Pers, 2012.

(12) Muhaimin, Arah Baru Pengembangan Pendidikan Islam Pemberdayaan, Pengembangan Kurikulum hingga Redefinisi Islamisasi Pengetahuan, Bandung: Nuansa, 2003.

(13) Mulyana, Deddy. Metodologi Penelitian Kualitatif. Bandung: PT Remaja Rosdakarya, 2003.

(14) Margono, S. Metodologi Penelitian Pendidikan . Cet. II; Jakarta: Rineka Cipta, 2000.

(15) Nasution, Zalkarimei. Teknologi Komunikasi Dalam Perspektif . Jakarta: Fakultas Ekonomi UI, 1989.

(16) Sugiyono. Metode Penelitian Pendidikan: Pendekatan Kuantitatif, Kualitatif, dan R\&D. Cet. VI; Bandung: Alfabeta, 2008. 
Marwiyah - Penggunaan Media Facebook Bagi Peningkatan Motivasi Belajar Siswa..

(17) S. Nasution. Berbagai Pendekatan Dalam Proses belajar Mengajar . Jakarta: Bumi Aksara, 2006

(18) S. Nasution. Teknologi Pendidikan. Bandung: Bumi Aksara, 2005.

(19) Uno, Hamzah B. Teori Motivasi dan Pengukurannya. Jakarta: PT. Bumi Aksara. 2008.

(20) Wahyudi, JB. Teknologi Informasi dan Produksi Citra Bergerak . Jakarta: Gramedia Pustaka Utama, 1992. 